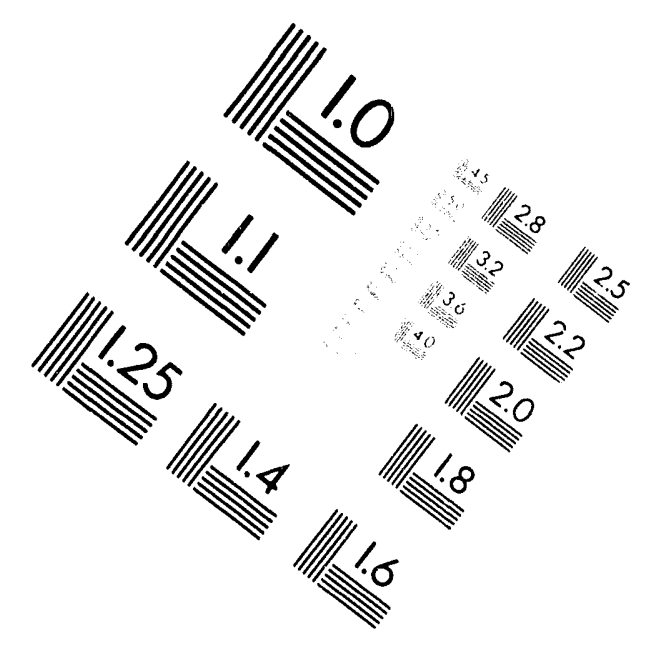

\title{
Centimeter
}

$\left.\right|_{11} ^{1}$ Inches
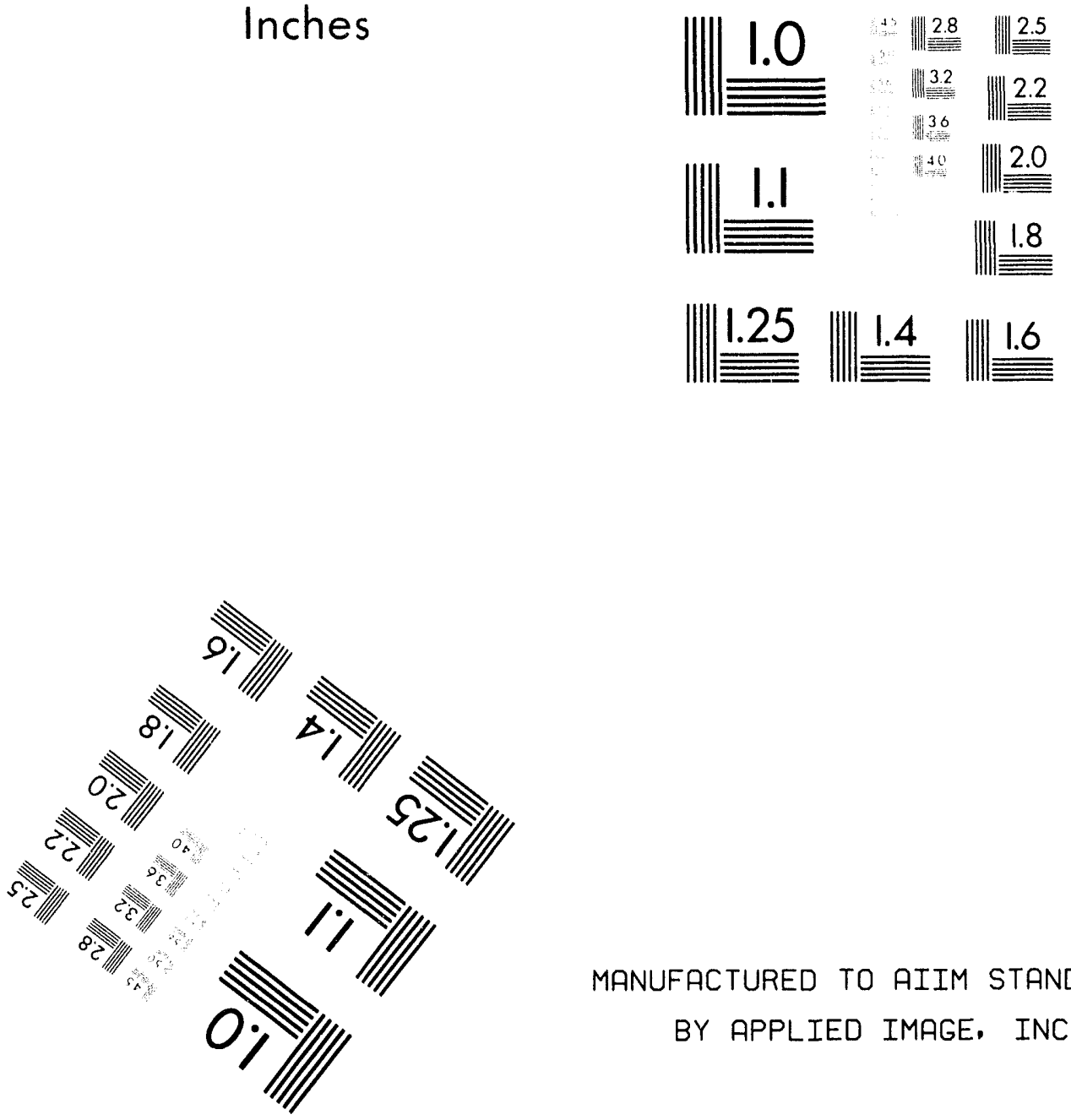

MANUFACTURED TO AIIM STANDARDS

BY APPLIED IMAGE, INC.

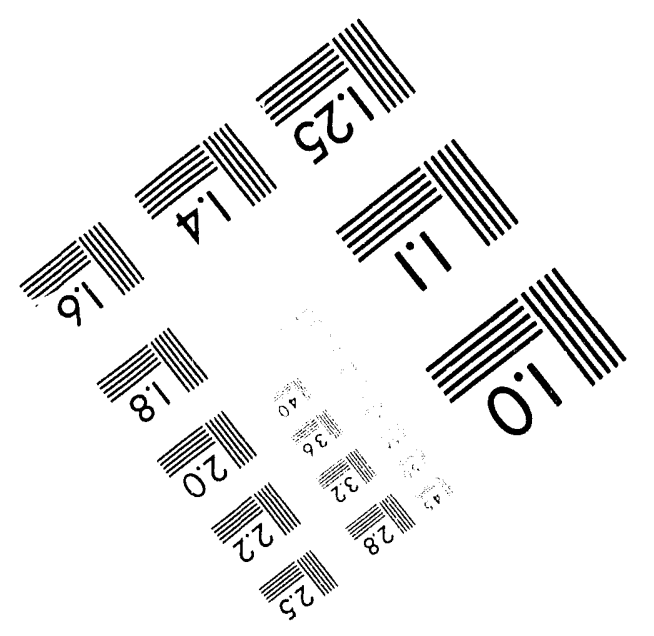



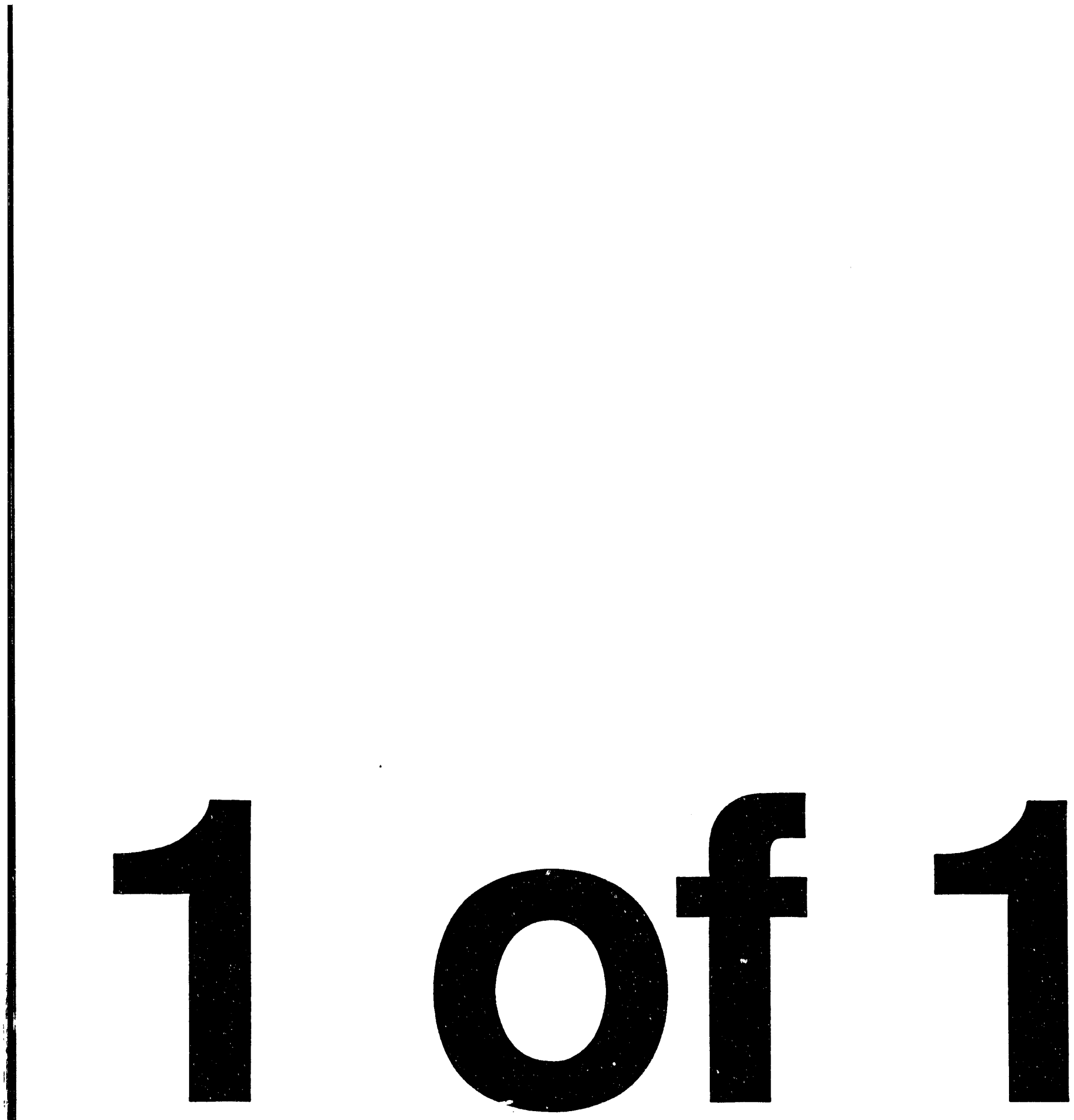


\section{IN-SITU MONITORING OF ACTINIDES AND RARE EARTH ELEMENTS BY ELECTROTHERMAL HOLLOW CATHODE DISCHARGE SPECTROMETRY}

Sang C. Lee and M. C. Edelson

Prepared for the Office of Safeguards and Security and the Idaho National Engineering Laboratory Buried Waste Integrated Demonstration Program

Date Transmitted: December 1992

\section{DISCLAIMER}

This report was prepared as an account of work sponsored by an agency of the United States This report was prepared as an account of work sponsored by an agency thereof, nor any of their Government. Neither the United States Government nor any agency thereof, nor any of theiremployees, makes any warranty, express or implied, or assumes any legal hability or refortuct, or bility for the accuracy, completeness, or usefulness of any information, appat rights. Referprocess disclosed, or represents that its use would not infringe privately owned rights. Refer-
ence herein to any specific commercial product, process, or service by trade name, trademark, manufacturer, or otherwise does not necessarily constitute or imply its endorsement, recommendation, or favoring by the United States Government or any agency thereof. The views and opinions of authors expressed herein do not necessarily state or reflect those of the United States Government or any agency thereof. 


\title{
IN-SITU MIONITORING OF ACTINIDES AND RARE EARTH ELEMENTS IN SOILS AND DUSTS BY ELECTROTHERMAL HOLLOW CATHODE DISCHARGE SPECTROMETRY
}

\author{
Sang C. Lee And i.f. C. Edelson \\ Technical Progress Report
}

Date Transmitted: December 1992

Prepared for the Office of Safeguards and Security and the Idaho National Engineering Laboratory Buried Waste Integrated Demonstration Program 
TABLE OF CONTENTS

TABLE OF CONTENTS ii

ABSTRACT iii

INTRODUCTION 1

RESEARCH SUMMARY 1

1. PURPOSE 1

2. PROGRESS 2

2.1 Instrumentation 2

2.2 Emission \& At,sorption Spectral Analysis 6

$\begin{array}{ll}\text { 2.2.1 Calibration } & 7\end{array}$

2.2.2 Argon Emission $\quad 7$

2.2.3 Air Emission 9

3. SUMMARY 11

4. FUTURE WORK 11

5. CITED REFERENCES 12

APPENDIX (Work Plan For BWID Demonstration) 13

DISTRIBUTION LIST $\quad 14$ 


\begin{abstract}
The construction of an improved glow discharge spectrometer is reviewed and a preliminary demonstration of continuous gas monitoring using this instrumentation is presented.

The emission spectra of many inert gases and air are measured to test the apparatus and to obtain information about background features that could interfere with the detection of the emission spectra of important analytes such as uranium or plutonium. A description of future instrumental work involving the use of electrothermal heating to volatilize materials for analysis is presented.

A work plan to prepare for participation at the 1993 Summer Technical Demonstration of the INEL BWID Program is presented.
\end{abstract}




\section{INTRODUCTION:}

This report describes an Electrothermal Hollow Cathode Discharge Spectrometry (ET-HCDS) source being constructed for the analytical determination of actinides and rare earth elements. This work was initiated with the support of the Office of Safeguards and Security; the Buried Waste Integrated Demonstration began funding work in this area in mid-FY1992 and the work is continuing into FY1993 with funds from both sources.

Special features of this instrument should permit it to be used for the determination of individual isotopic species, which is important for safeguard's materials control and accountancy. ET-HCDS can be achieved using compact instrumentation suitable for use in field laboratories. The technique is capable of determining a suite of environmentally-important species, such as the actinides and the heavy metals, in a variety of physical forms (e.g., in solution, as found on air particulates, or in soils). ET-HCDS should be capable of very sensitive analyses and should require very small samples (e.g., microgram).

Since ET-HCDS is possible in an air atmosphere (at reduced pressures), it may be useful for the real-time determination of hazardous materials, both radioactive and non radioactive, contained in dusts released during waste retrieval operations; ET-HCDS should also be useful for the rapid and sensitive analysis of metals in soils.

\section{RESEARCH SUMMARY:}

\section{Background:}

We are developing a new instrument for measuring the concentration of hazardous materials, including both radioactive and nonradioactive elements, in a contaminated area. This instrument contains a compact and stable atomization source that features a hollow cathode discharge located in an electrothermal furnace. Notably, the first observation of uranium and thorium atoms via commercial diode lasers was demonstrated on actinide atoms in a hollow cathode lamp[1,2]. These experiments were accomplished using a relatively low-cost, compact, diode laser system that holds promise for the field analysis of actinides by ET-HCDS.

Glow discharges have long been used for the emission spectral analysis of metal atoms[3,4]. In 1985 Falk and coworkers developed a glow discharge technique with better detection limits than graphite furnace atomic absorption spectrometry or inductively coupled plasma-atomic emission spectrometry[5]. This technique, known as Furnace Atomic Nonthermal Excitation Spectrometry (FANES), utilized a glow discharge contained in a graphite furnace. The original implementation of FANES would not permit its use for continuous monitoring and involved the use of very large power supplies that precluded its use as instrumentation for field analysis. The FANES cell design also required complex machining of insulator supports. 


\section{Progress:}

To achieve in-situ monitoring of actinides and other hazardous metals via diode laser spectrometry, we have designed an instrument that is compact and combines the features of an atomization/emission source with electrothermal heating and hollow cathode discharge. It should possess the advantages of versatile sample introduction (either continuous $\mathrm{nr}$ static), compactness and portability, high atomization efficiency, fast analysis time, and multielement detection. This instrument, which features a source modeled after the FANES source, should be more compact than FANES instrumentation and is designed to facilitate the application of laser spectroscopy to materials in the vapor phase.

The construction of the ET-HCDS source is almost completed but the electrothermal furnace unit has not been fully implemented. Thus, the source has only been tested in the "hollow cathode" mode. The emission spectra of several inert gases were generated and analyzed. Argon, helium, xenon, krypton, nitrogen, and air were studied. These initial tests without electrothermal heating provided meaningful information about the hollow cathode discharge of various gases in continuous flow. The negative glow formed in the cathode remained steady for long periods of time and was easily reproduced. Noticeably, the air glow discharge in a tantalum cathode was quite stable in continuous flow. This suggests that the real-time monitoring of dusts can be done by introducing air directly into a hot hollow cathode where adsorbed species would be volatilized into the glow discharge for spectroscopic analysis. Also, the electrothermal feature of the device may be able to directly volatilize elements in soils so $t^{\circ}$ at they can be analyzed without pretreatment. In FANES work with graphite cathodes [5], temperatures of $\sim 3000 \mathrm{~K}$ could be reached very quickly so that samples were volatilized from the cathode in less than a second.

Falk [5] noted that the detection limits of FANES were limited by background molecular emission structure caused by carrier gas impurities and vacuum imperfections. For ET-HCDS to achieve excellent detection limits in a carrier gas totally composed of molecular constituents will require careful spectroscopic optimization so that diode laser and analvte lines are chosen that do not have molecular band interference.

\subsection{Instrumentation}

A schematic diagram of the current ET-HCDS source is shown in Figure 1. Also, the xenon negative glow created in a tantalum hollow cathode is shown in Figure 2. The ET-HCDS was constructed with tantalum tubes in place of graphite tubes to facilitate the study of uranium, which forms refractory carbides upon contact with hot graphite, and to produce a more stable glow discharge than would be expected using graphite. The schematic diagram of the electrothermal hollow cathode discharge source is shown in Figure 3. A smaller Ta tube $\left(1 / 4^{n}\right.$ diameter) was used as the cathode and a larger Ta tube $\left(1 / 2^{n}\right.$ diameter) as an electrothermal furnace. This design creates a glow discharge inside of the cathode at low voltage and also improves the stability of the glow discharge. A listing of the experimental apparatus is given in Table 1. 


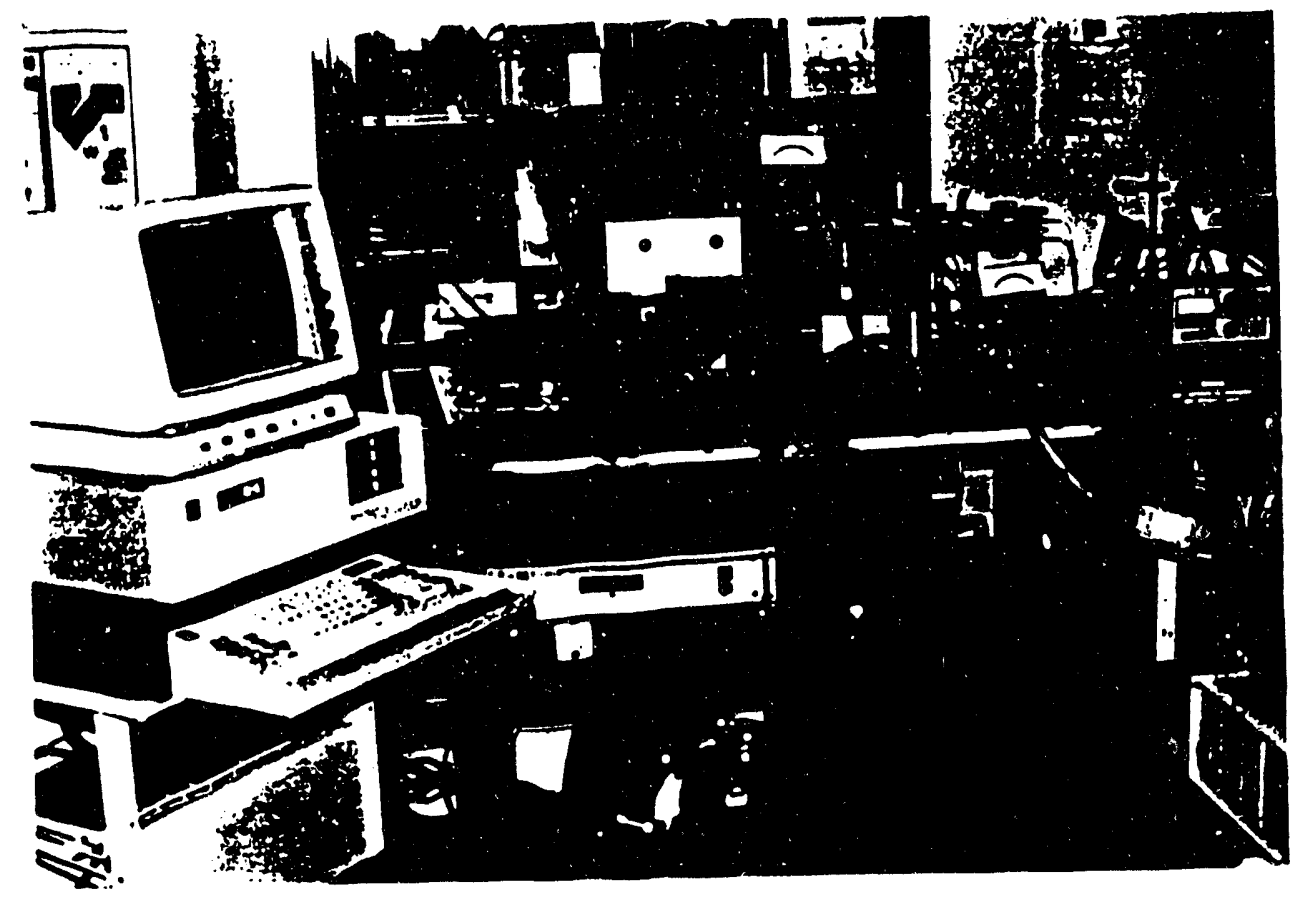

Figure 1 Electrothermal Hollow Cathode Discharge Spectrometry source equipped with an OMA (Optical Multichannel Analyzer) detector for emission and absorption spectral analysis.

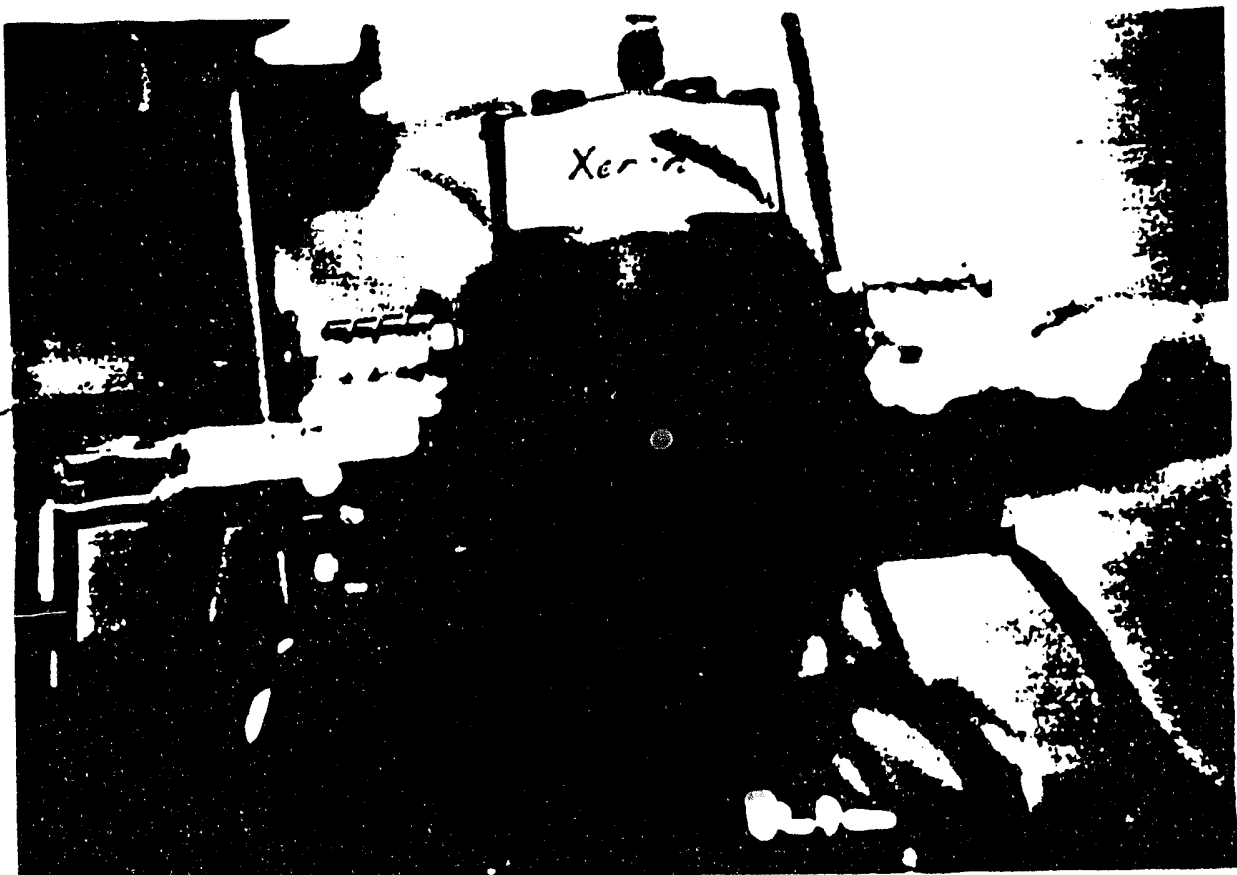

Figure 2 Xenon glow discharge formed in a tantalum tollow cathode. Table 1. Experimental apparatus. 
A. ET-HCD Source

Power Supply

Vacuum Pump

Model 205B-01R

Bertan Associates

TC Vacuum Gauge

Duo-Seal

Type 0531

Welch

Vacuum Gauge Meter

Model 803

Varian

Flow Meter

$65 \mathrm{~mm}$ variable area

Varian

Cole Parmer

B. Spectrometer

Grating

$0.32 \mathrm{~m}, \mathrm{f} / 4 \mathrm{HR}-320$

Instruments SA

C. Detector

OSMA

OSMA Controller

Model RY-1024

Princeton Instruments

Model ST-110

Princeton Instruments

D. Diode Laser

Laser Diode Driver

Thermoelectric

Controller

Temperature Head

Laser Diode

Model LD-2000

Seastar Optics

Model TC-5100

Model AC 9550

Model HL7801E

Seastar Optics

Seastar Optics

Hitachi

E. Computer

IBM AT

F. Software

Princeton Instruments

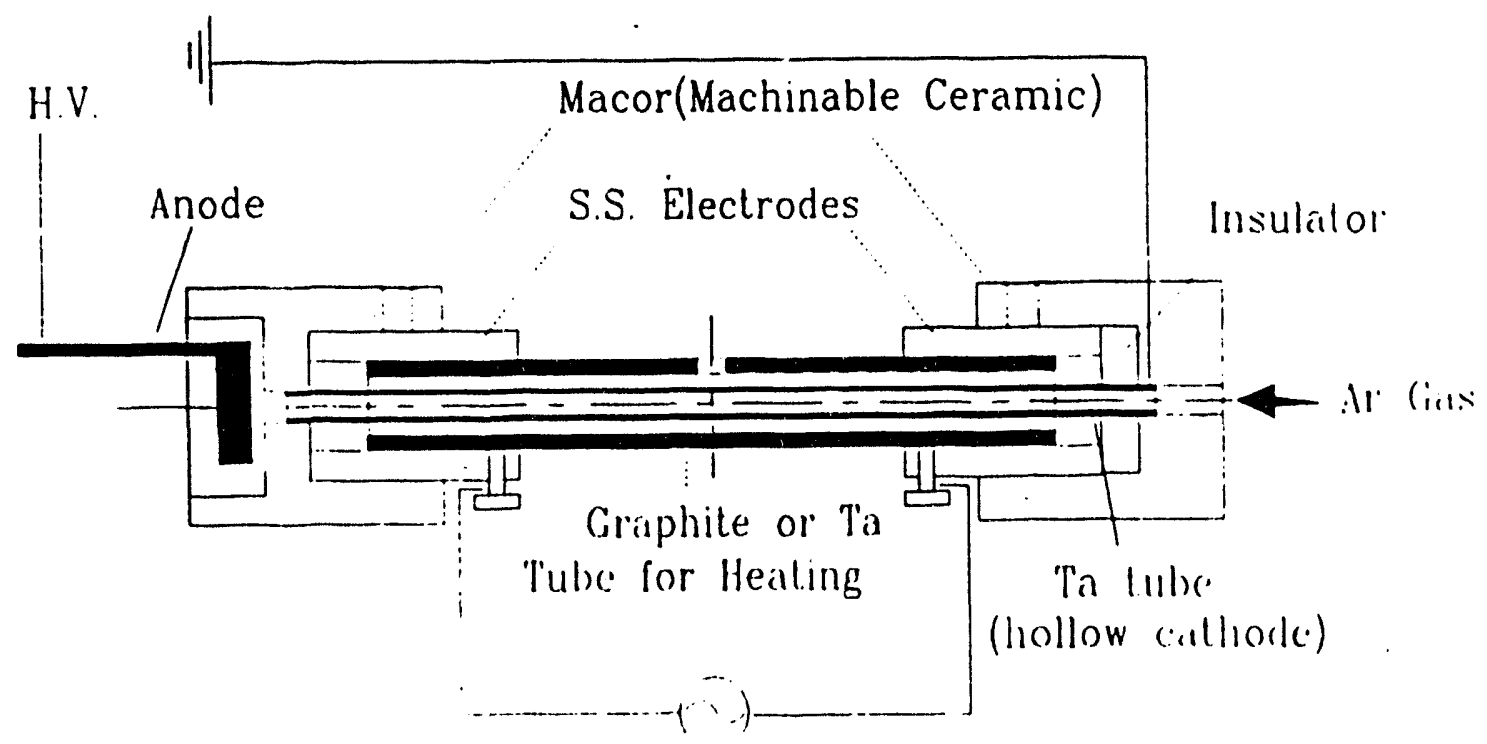

Figure 3 Schematic of the electrothermal hollow cathode discharge cell. 
A flow meter with shut-off valves at the gas inlet and outlet ports was used to control the flow rate of carrier gases. Consistent carrier gas flow rates were critical to the stability of the glow discharge. Solid or gaseous samples will be placed directly onto the cathode without pretreatment. The ET-HCDS source requires two power supplies, one for the negative glow discharge and the other for electrothermal heating. At the beginning of an experiment, the whole system needs to be evacuated to 10 to 100 mtorr by a mechanical vacuum pump. When carrier gases were present, the system pressure was kept at 1-2 torr for stable operation. Two thermocouple vacuum gauges were employed to monitor the pressure of ET-HCDS. The configuration of the ET-HCDS experimental arrangement is shown in Figure 4.

For rapid multielemental analysis a small monochromator using an optical multichannel detector will be used for emission spectral detection. The optical arrangement includes three optical windows. The two in-line windows can be used for laser absorption studies and the third, which can be used for fluorescence measurements but isn't shown on Figure 4 , is positioned at $90^{\circ}$ to the instrument optical axis to view the glow discharge near the sample injection point. Laser techniques, such as saturated absorption spectrometry, that feature better than Doppler-limited resolution, can be employed to facilitate the measurement of individual actinide isotopes if the emission spectra produced by ET-HCDS lack the necessary resolution. If remote detection is needed, fiber optics can be mounted on each side of the in-line windows to deliver laser light to the sample vapor and/or to collect the light emitted by samples for remote analysis. Both the rare earth and actinide elements have rich spectra in the near infra-red spectrum where both diode lasers and fiber optics operate efficiently.

\subsection{Emission and Absorption Spectral Analysis}

Emission spectra of several inert gases, i.e., argon, helium, krypton, and xenon, continually introduced to the ET-HCDS source were studied to determine whether their emission lines would interfere with the detection of important analytes. The ET-HCDS set-up used to generate these emission spectra is shown in Figure 5. This report includes only the portion of the spectra in the region of $750-810 \mathrm{~nm}$ (the region covered by commercial diode lasers currently used in our laboratory). The emission spectrum of laboratory air was also investigated.

We also tested the ET-HCDS for solution analysis by nebulizing a 1000 ppm rubidium standard solution with an ultrasonic nebulizer and sending the $\mathrm{Rb}$-laden argon gas stream into the cell. This configuration permits continuous monitoring of liquids and consumes only microliters of solution per minute. The strongest rubidium emission line $(780.0 \mathrm{~nm})$ was successfully detected. Since the ET-HCDS cell, without electrothermal heating, cannot handle solution analysis efficiently, the detection efficiency was poor. We expect substantial improvements in sensitivity after an electrothermal heater is installed. 


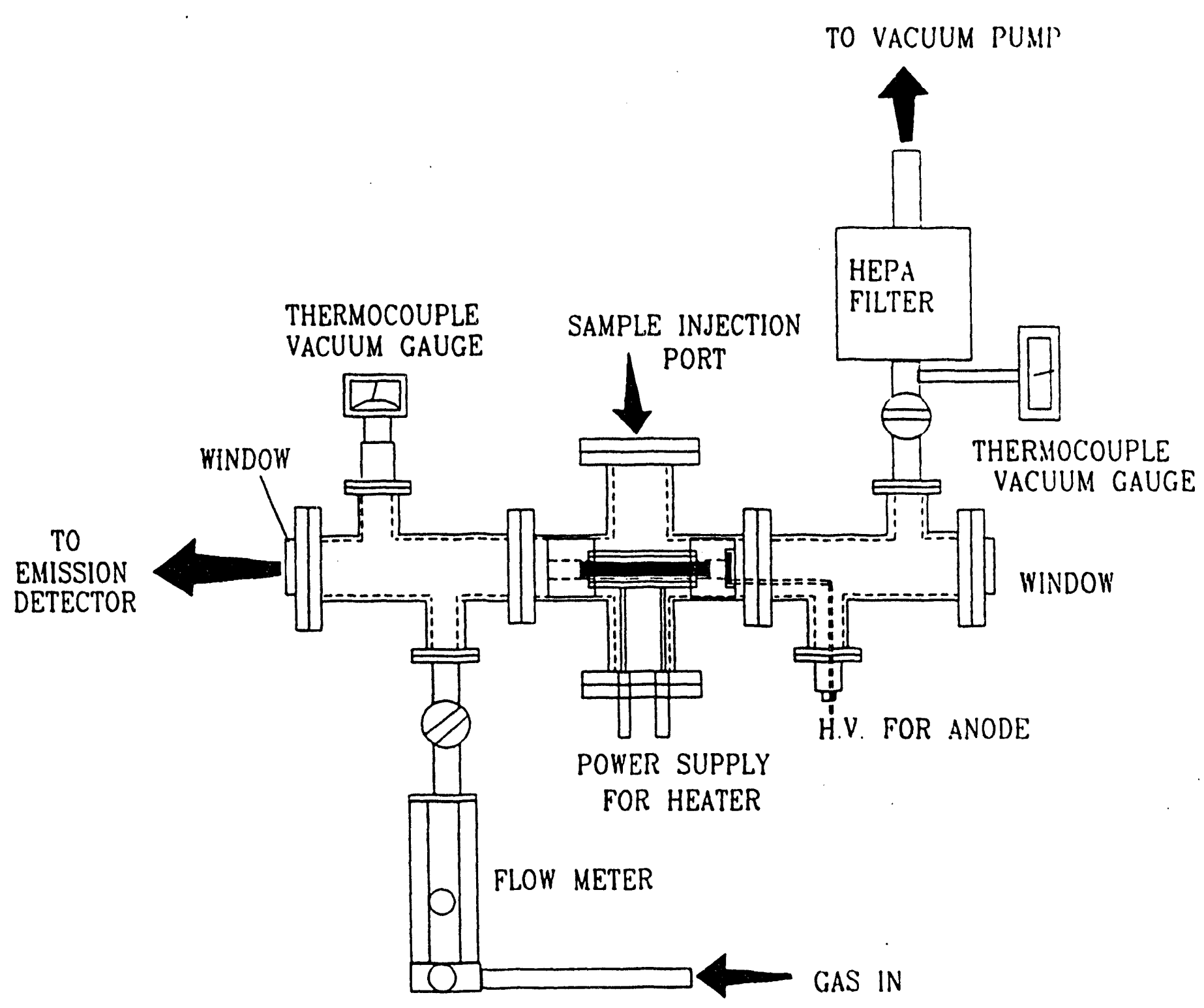

Figure 4 Overall schematic of ET-HCDS apparatus. 


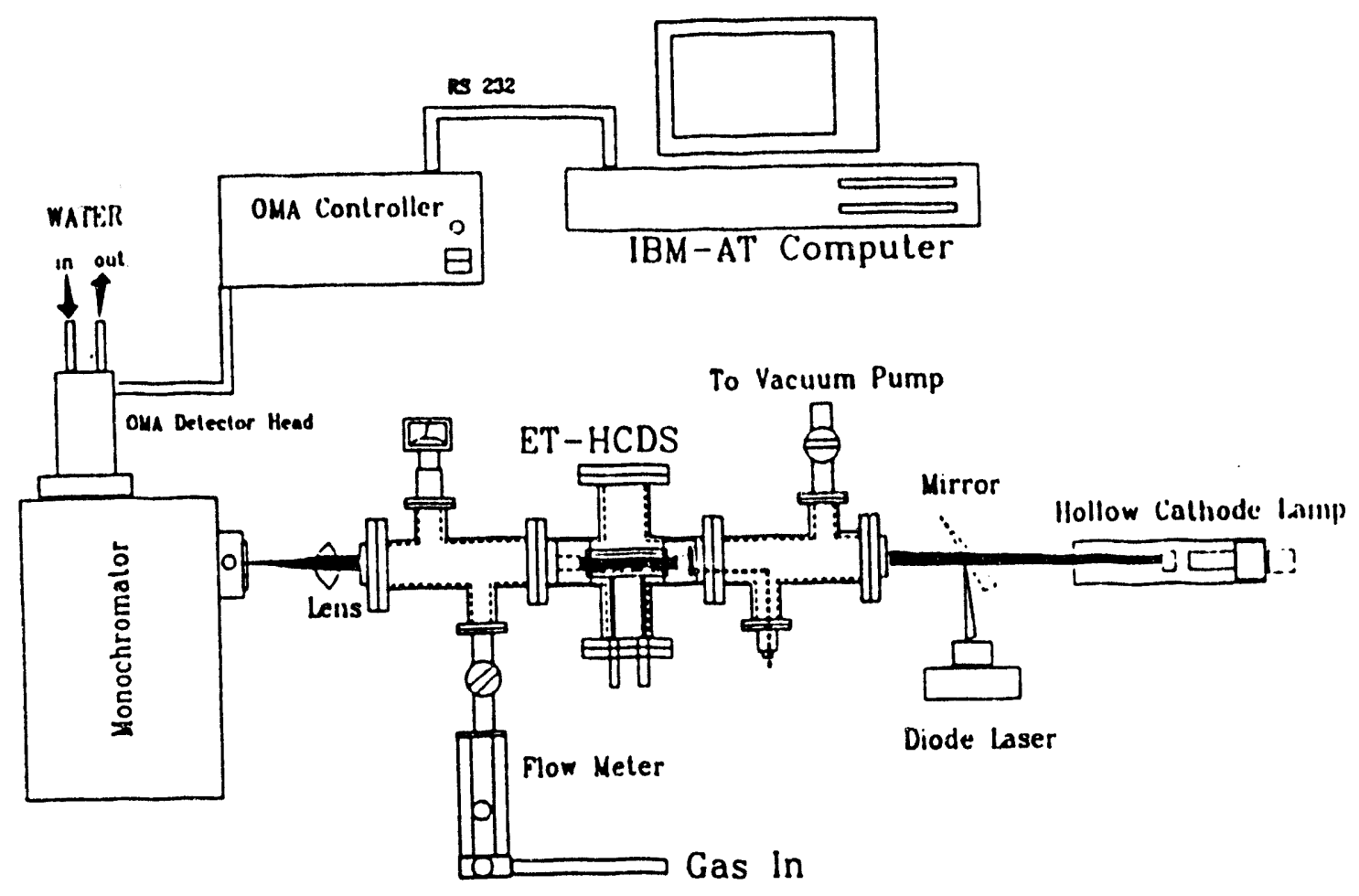

Figure 5 Schematic of ET-HCDS set-up for emission and absorption spectral analysis

\subsubsection{Calibration}

An argon-filled uranium hollow cathode lamp was used for the wavelength calibration of ET-HCDS emission spectra. All the argon emission lines were previously reported [6]. This method provided a precise calibration of the wavelengths observed in the emission spectra collected by an optical multichannel detector. The argon emission spectrum from a hollow cathode lamp (HCL) is shown in Figure 6. These argon emission lines are two to three orders of magnitude more intense than the $U$ lines in the same spectral region. The optical multichannel detector integration time was extended to increase sensitivity and observe $U$ emission lines (Figure 7).

\subsubsection{Argon Emission}

Argon, which has a relatively low intensity background emission in the discharge over a wide spectral range and forms a stable plasma, can be used as a carrier gas for ET-HCDS. A photograph of the argon plasma formed in the ETHCDS source with a tantalum cathode is shown in Figure 8. The plasma was very uniform and the tantalum sputtering efficiency was reasonably good. Argon emission spectra in $300-900 \mathrm{~nm}$ were investigated and the spectra were compared with the emission spectra produced by an argon-filled hollow cathode discharge lamp. Strong tantalum emission lines due to the cathode surface sputtering were observed. The emission spectrum of the ET-HCDS discharge over the $755-805 \mathrm{~nm}$ wavelength range, is shown in Figure 9. 


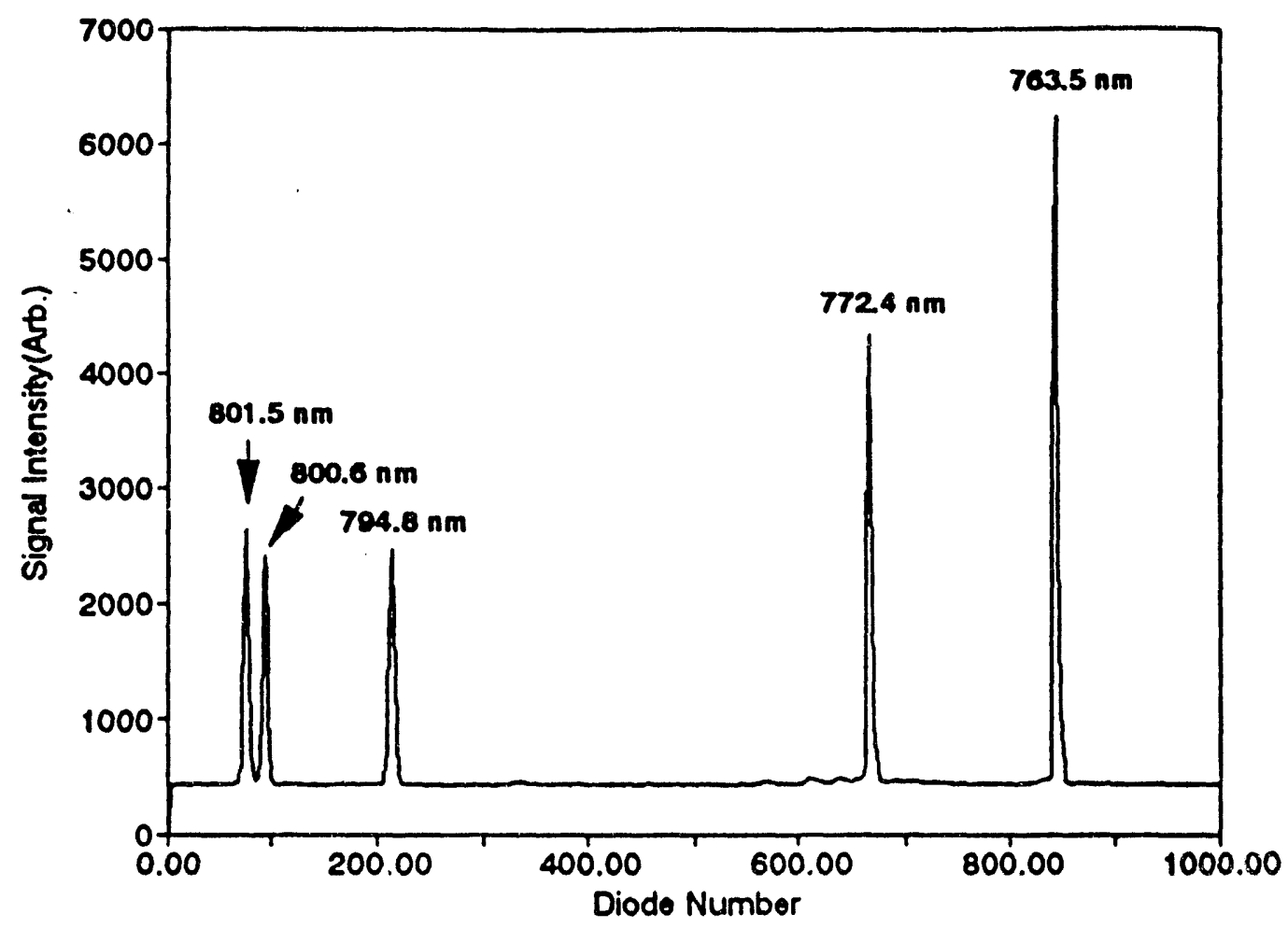

Figure 6 Argon emission spectrum of a commercial hollow cathode lamp. The discharge current was $15 \mathrm{~mA}$ and monochromator was set at $780 \mathrm{~nm}$. The signal integration time was $\sim 1.6$ seconds.

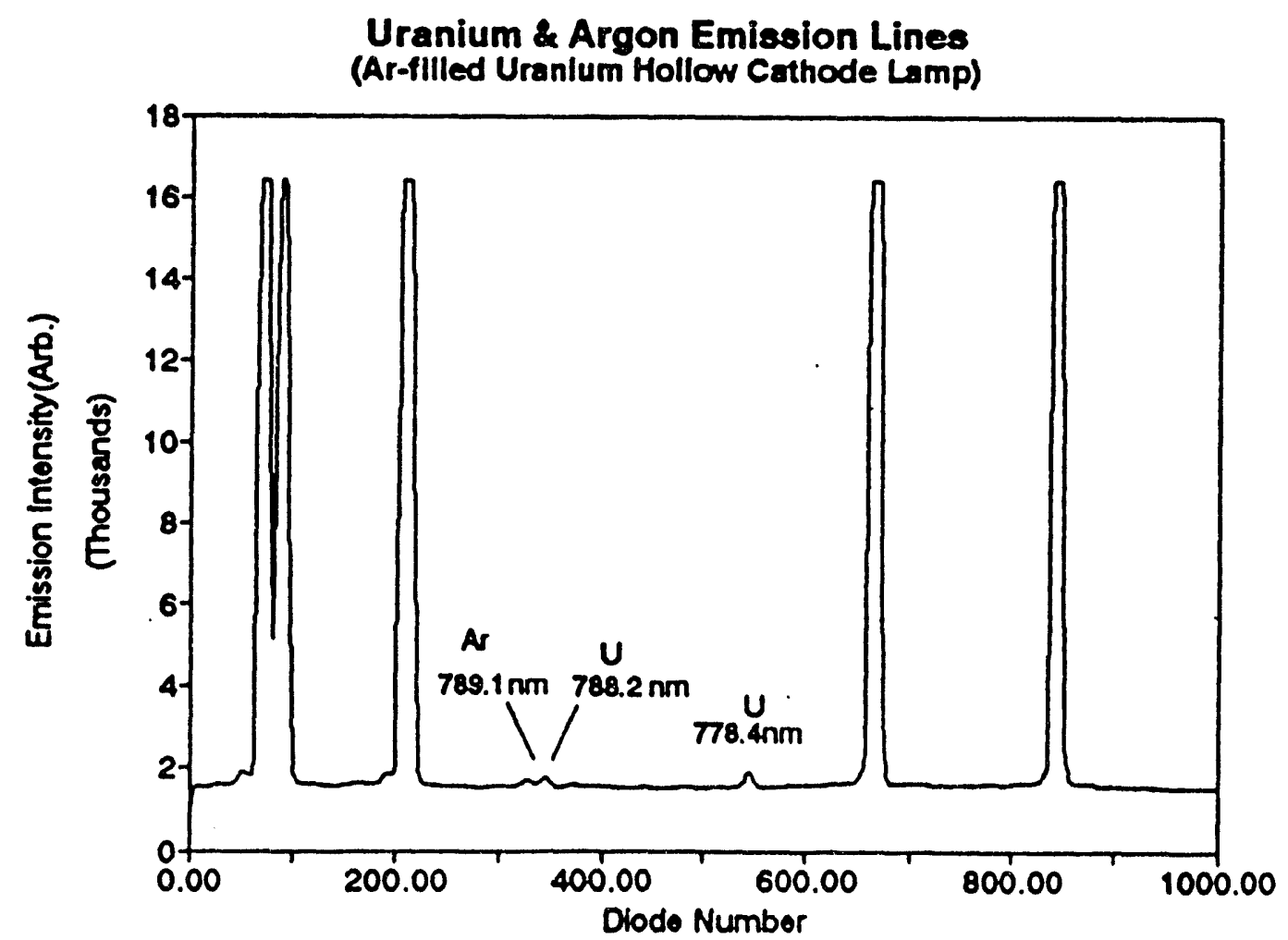

Figure 7 Low intensity $U$ emission from commercial hollow cathode lamp (same lamp as used in Fig. 6). The signal integration time was 66.6 seconds. 


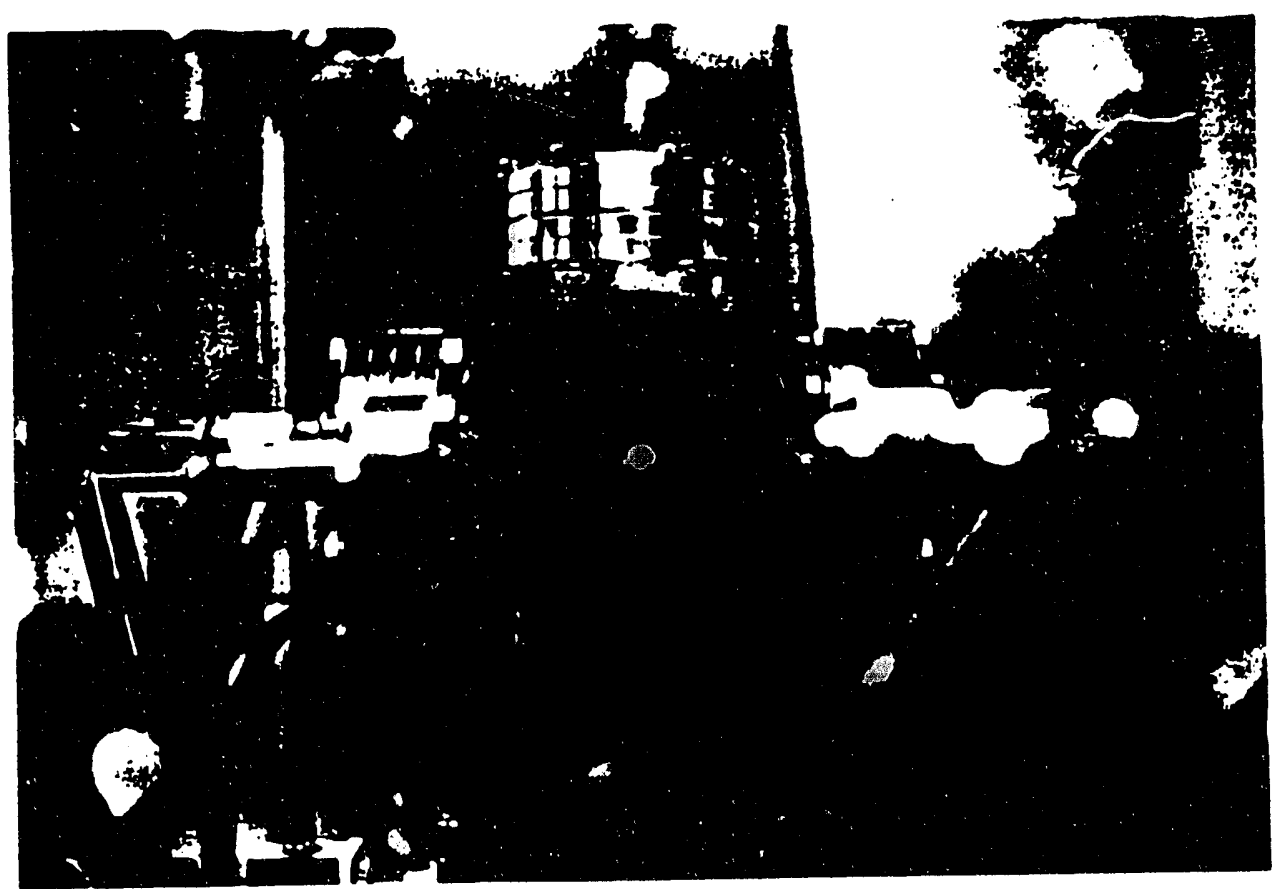

Figure 8 Argon plasma formed in the tantalum cathode by ET-HCDS.

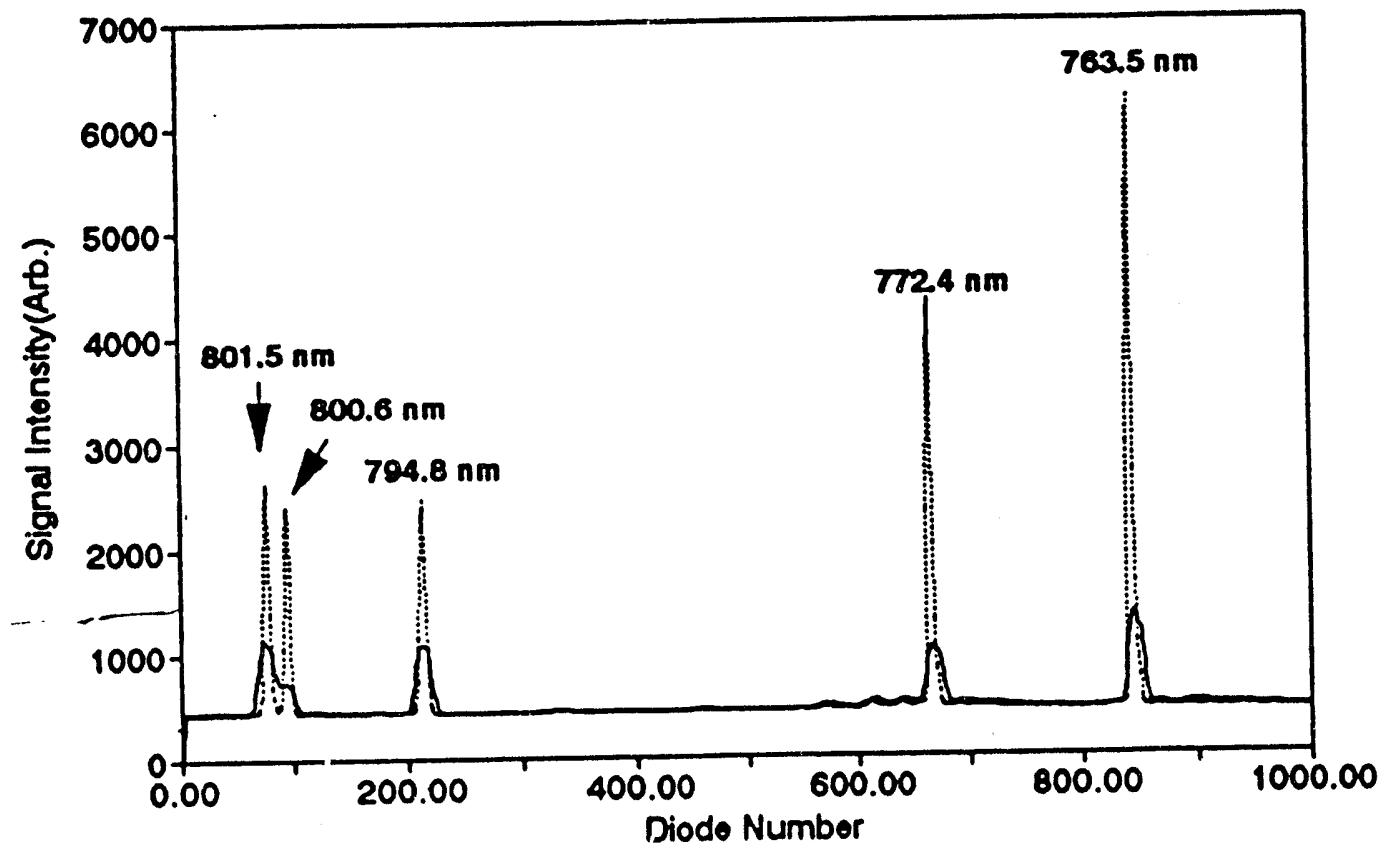

\section{$\mathrm{HCL} \longrightarrow$ Argon}

Figure 9 Emission spectrum of argon glow discharge in the tantalum cathode by ET-HCDS. Argon flowed at $150 \mathrm{ml} / \mathrm{min}$. and $5 \mathrm{~mA}$ discharge current was maintained. 


\subsubsection{Glow Discharge in Air}

If air can be used as carrier gas in ET-HCDS, field monitoring will be facilitated and ET-HCDS will be a more practical technique for the continuous monitoring of dusts. The air emission spectrum from the ET-HCDS discharge was investigated. A photograph of the glow discharge from air is shown in Figure 10. The emission spectrum of laboratory air was more complicated than were the emission spectra of the inert gases. This complexity in plasma spectra was due to strong molecular emission from the nitrogen molecules in air. To find analytically useful spectral regions with air as a carrier gas, the $300-900 \mathrm{~nm}$ region was thoroughly investigated. Most spectral regions contained molecular bands but some were relatively clear and thus potentially useful for the determination of actinides and rare earths. The air emission spectrum in the $755.805 \mathrm{~nm}$ wavelength range is shown in Figure 11 along with the spectrum of a hollow-cathode lamp containing argon over the same wavelength range.

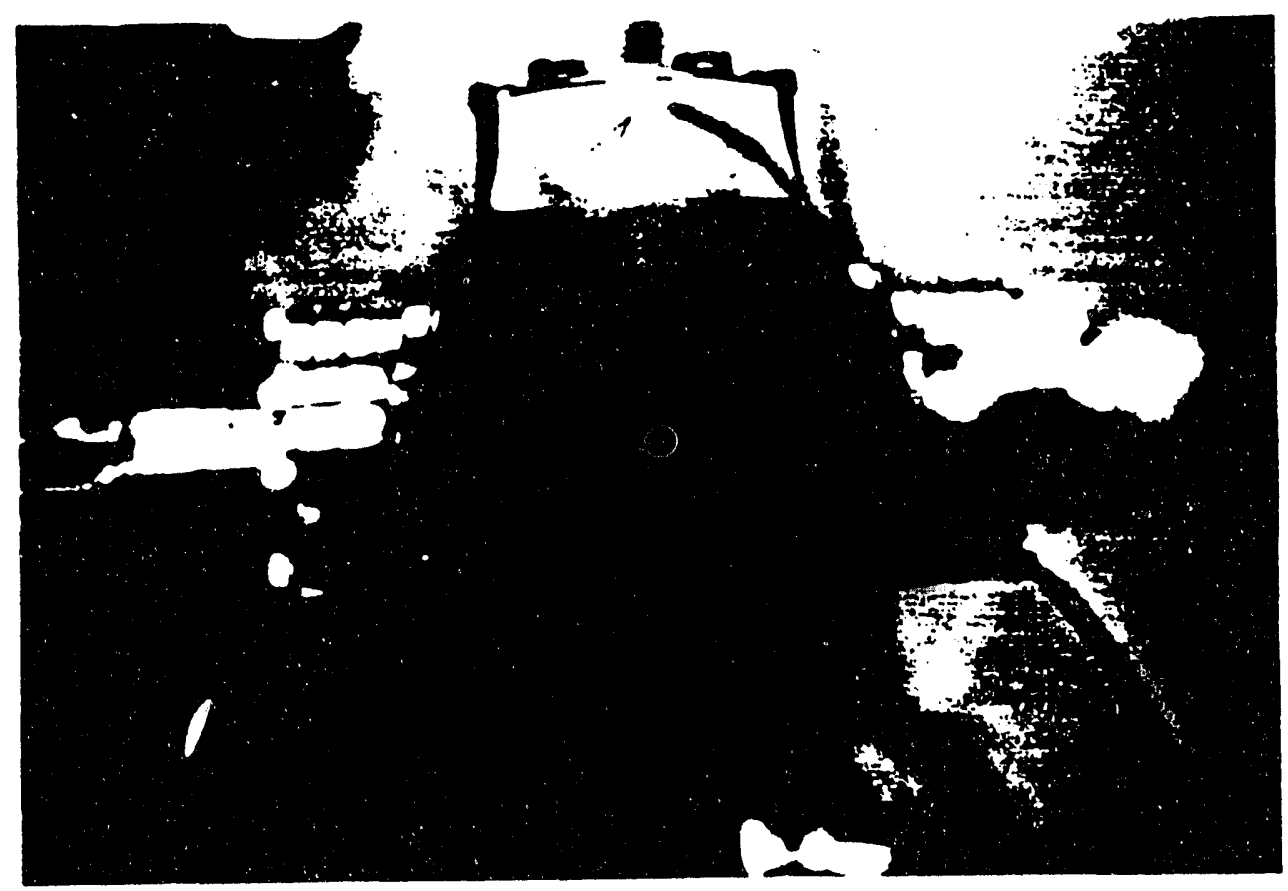

Figure 10 Air glow discharge in the tantalum cathode of ET-HCDS. Air was continuously flowed at $200 \mathrm{ml} / \mathrm{min}$. and discharge current was $10 \mathrm{~mA}$. 


\section{SUMMARY}

A new apparatus has been constructed to monitor actirides and rare earth elements. This apparatus, which relies upon Electrothermal - Hollow Cathode Discharge Spectrometry, is currently being tested and modified to improve its analytical performance and to permit easy sample introduction. Background emission spectra of likely carrier gases (e.g., air, xenon, krypton, helium, nitrogen. and argon) have been generated and analyzed. The ET-HCDS source produced a glow discharge during continuous introduction of gases that was quite stable and reproducible. The instrument will be tested to determine its applicability to the determination of actinides in solution and soil matrices.

The Appendix lists a suggested workplan that will culminate in the demonstration of this apparatus at the Idaho National Engineering Laboratory's Summer Demonstration of technologies to support the Buried Waste Integrated Demonstration.

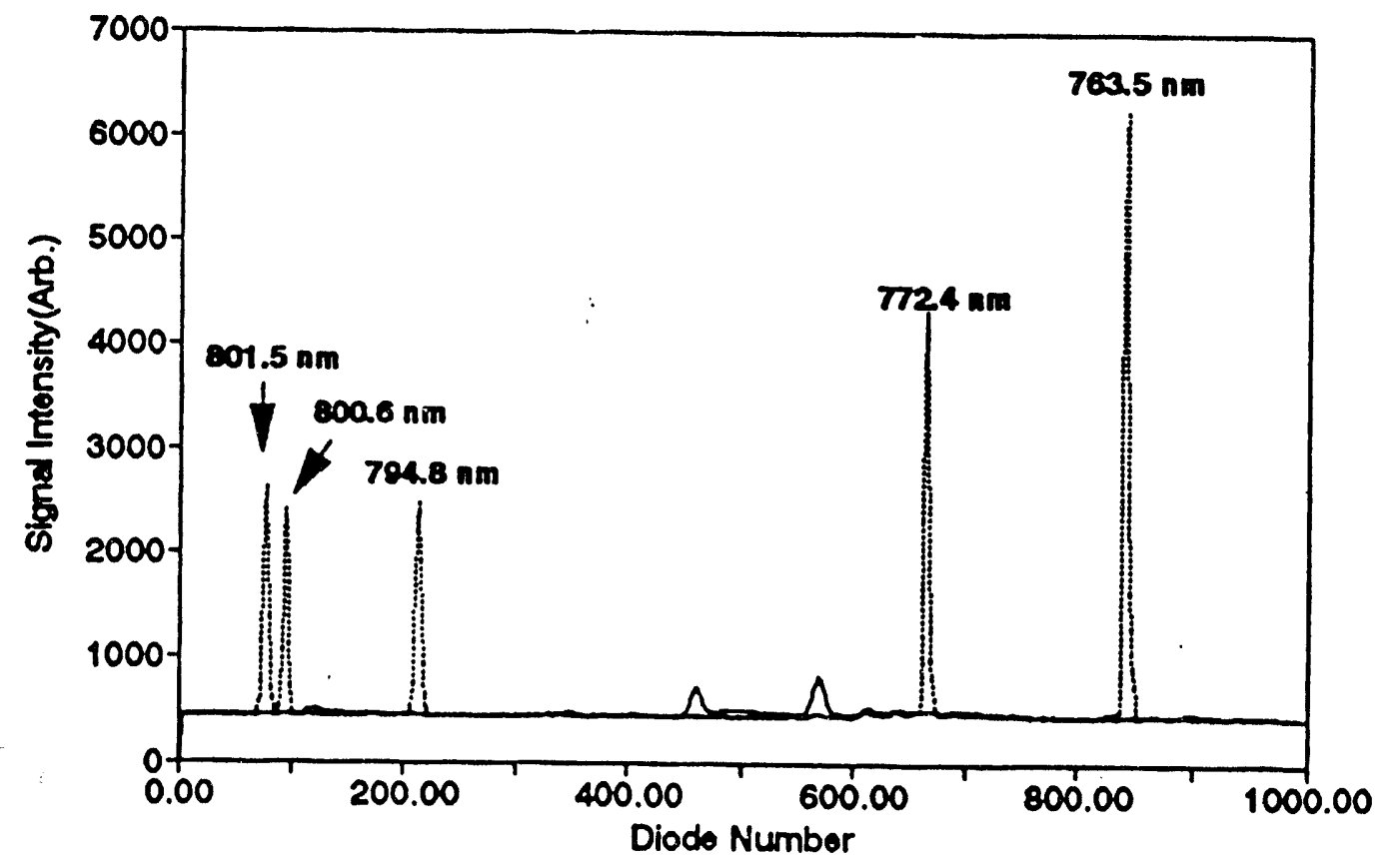

$\mathrm{HCL}-$ Air

Figure 11 Air emission spectrum in the $760-810 \mathrm{~nm}$ region. (Broken line spectrum from hollow cathode lamp (HCL) containing argon; Solid line - emission spectrum from ET-HCDS source). 


\section{FUTURE WORK}

The ET-HCDS source will be completed as soon as possible and then used to determine elements contained in NIST standard solutions as well as BWID soil samples [soil samples from the Cold Test Pit were requested from G. Loomis in September]. These tests will help determine the instrument detection limits, precision, and accuracy of ET-HCDS. The emission spectra of potential carrier gases, including air, will be thoroughly analyzed. Safety considerations and user operating procedures will be established. In addition, any necessary utilities and needed supplies for the implementation of the ET-HCDS in the INEL mobile lab will be specified after our own technical review of ET-HCDS is completed.

\section{REFERENCES}

[1] R.J. Lipert, S.C. Lee, and M.C. Edelson, "High Resolution Spectroscopy of Atomic Vapors Using Diode Lasers", FACSS XIX Proceeding, September 20-25, 1992

[2] S.C. Lee, R.J. Lipert, and M.C. Edelson, "First Observation of Actinide Elements by Optogalvanic Spectroscopy Using A Diode Laser Source", EACSS XIX Proceeding, September 20-25, 1992; R.J. Lipert, S.C. Lee, and M.C. Edelson, "Applications of Diode Lasers To Actinide Atom Monitoring", Appl.Spectrosc., 46, 1992, 1307-1308

[3] L.R.P. Butter, K. Kroger, and C.D. West, "Emission Spectral Analysis with the Glow Discharge Source and A Resonance Detector", Spectrochim. Acta 30B, $1975,489-499$

[4] J. Czahow, "The microcavity hollow cathode and its analytical potential", Improved Hollow Cathode Lamps For Atomic Spectroscopy, Edited by S. Caroli, Ellis Horwood, New York, 1985, 35-50

[5] H. Falk, E. Hoffmann, and C.H. Ludke, "A Comparison of Furnace Atomic Nonthermal Excitation Spectrometry (FANES) with Other Atomic Spectroscopic Techniques", Spectrochim. Acta 39B, 1984, 283-294

[6] American Institute Of Physics Handbook, 3rd Edition, Edited by Dwight E. Gray, et al., McGraw-Hill Book Company, New York, 1972 


\section{APPENDIX}

\section{AMES WORK PLAN:}

November - December 31, 1992:

* Complete ET-HCDS construction.

* Complete emission spectral analysis of carrier gases

January 1-January 31, 1993

* Perform analyses of standard solutions and soil samples with the ET-HCDS via emission spectroscopy.

* Evaluate the trace analysis of rare earth elements with the ET-HCDS via emission spectroscopy.

February 1-February 28, 1993

* Issue report describing January results.

* Include diode lasers as sources for ET-HCDS.

* Continue trace analysis of rare earth elements.

* Contact Dr. Loomis to check the possibility of installation of ET-HCDS in INEL mobile laboratory.

March 1- April 30, 1993

* Test soil samples and dusts with ET-HCDS.

* Prepare for the BWID technology summer demonstration.

* Issue report describing the analytical performance of ET-HCDS.

May 1-May 31, 1993

* Finalize all the safety operating procedures.

* Finish preparations for the 1993 Summer Technology Demonstration at the INEL BWID Program.

June 1993

* Demonstrate ET-HCDS at INEL. 


\section{DISTRIBUTION LIST}

\section{OSS}

Mr. Edward J. McCallum, Director

Office of Safeguards and Security, SA-10

U.S. Department of Energy

Washington, D.C. 20585

Mr. David Crawford, Chief

Materials Control and Accountability Branch, SA-124

Office of Safeguards and Security

U.S. Department of Energy

Washington, D.C. 20585

Mr. Jerry Howell, Director

Field Operations Division, SA-13

Office of Safeguards and Security

U.S. Department of Energy

Washington, D.C. 20585

Dr. G. Dan Smith, Chief

Planning and Technology Development Branch, SA-134

Office of Safeguards and Security

U.S. Department of Energy

Washington, D.C. 20585

Mr. David Jones, Director

Policy, Standards, and Analysis Division, SA-12

Office of Safeguards and Security

U.S. Department of Energy

Washington, D.C. 20585

\section{BWID}

Mr. S. Kenneth Merrill, Coordinator

Buried Waste Integrated Demonstration

Idaho Nuclear Engineering Laboratory

EG\&G Idaho, Inc.

P.O. Box 1625

Idahc Falls, ID 83415

Mr. Kevin M. Kostelnik, Project Manager

Buried Waste Integrated Demonstration

Idaho Nuclear Engineering Laboratory

EG\&G Idaho, Inc.

P.O. Box 1625

Idaho Falls, ID 83415 
AMES

Dr. James C. Corones, Technical Program Manager

Director, Environmental Technology Development Program

Ames Laboratory

Iowa ritate University

Ames, IA 50011

Dr. William J. Haas, Jr.

Assistant Director, Environmental Technology Development Program

Ames Laboratory

Iowa State Unversity

Ames, IA 50011

Dr. Martin Edelson

Director, Nuclear Materials Safeguards \& Security Program

Assistant Director, Environmental Technology Development Program

Ames Laboratory

Iowa State University

Ames, IA 50011

Prof. T. J. Barton, Director

Ames Laboratory

Iowa State University

Ames, IA 50011

Mr. Lowell Mathison

Ames Laboratory

Iowa State University

Ames, IA 50011

Ms. Beth Weiser

Office of Information

Ames Laboratory

Iowa State University

Ames, IA 50011

\section{Chicago Field Office}

Mr. Joel Haugen, Technical Project Officer

Chicago Field Office

U.S. Department of Energy

9800 South Cass Avenue

Argonne, IL 60439

Mr. Steven Webster

Chicago Field Office

U.S. Department of Energy

9800 South Cass Avenue

Argonne, IL 60439 
Mr. C. E. Pietri

Physical Science Administrator

Chicago Field Office

U.S. Department of Energy

9800 South Cass Avenue

Argonne, IL 60439

Patent Office, USDOE

Chicago Field Office

9800 South Cass Avenue

Argonne, IL 60439

Technical Information Center

USDOE-TIC

Oak Ridge National Laboratory

P.O. Box 62

Oak Ridge, TN 37830 

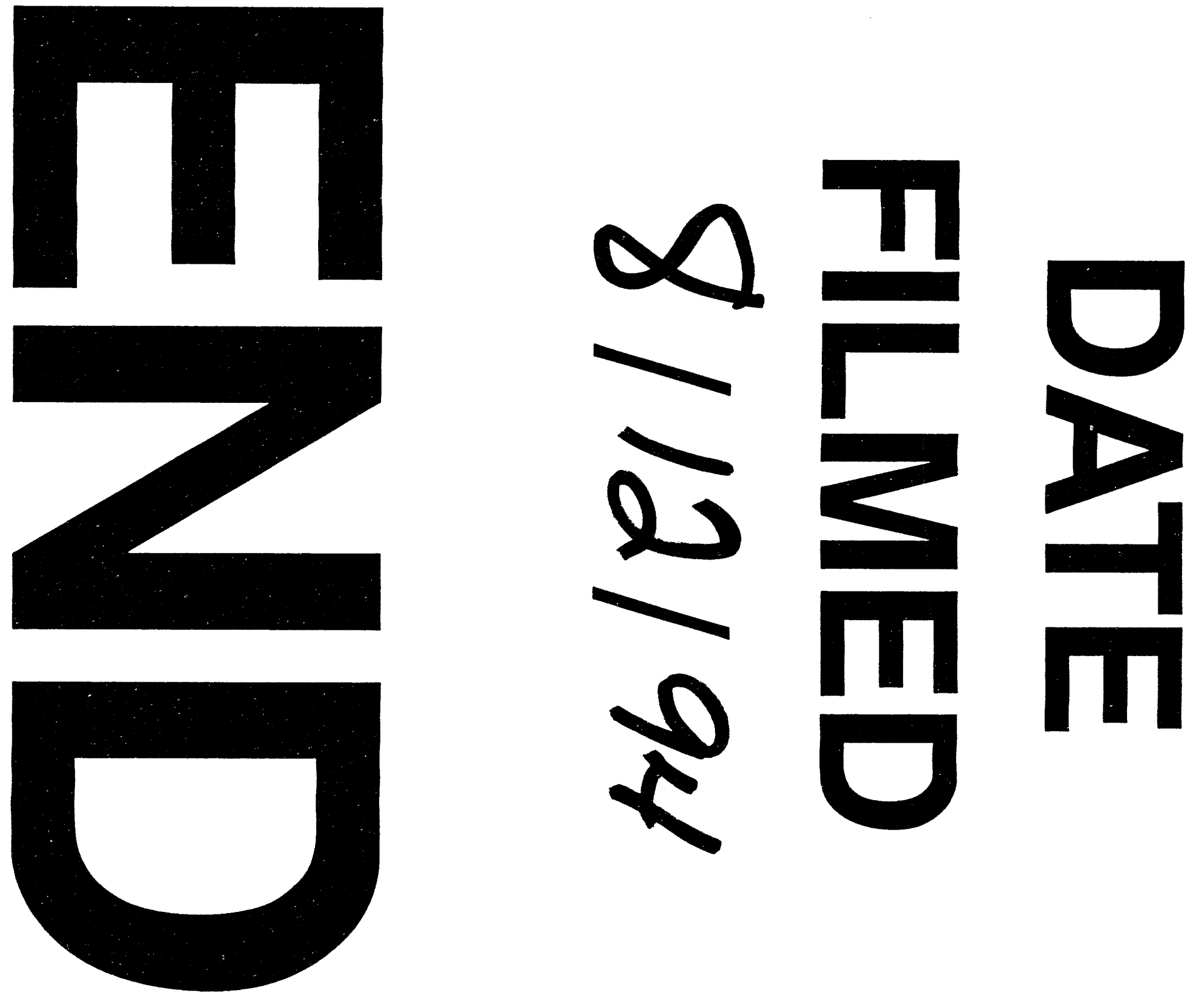

$\circlearrowright$
$\stackrel{O}{\rho}$
$\mathrm{H}$ 
Dim 